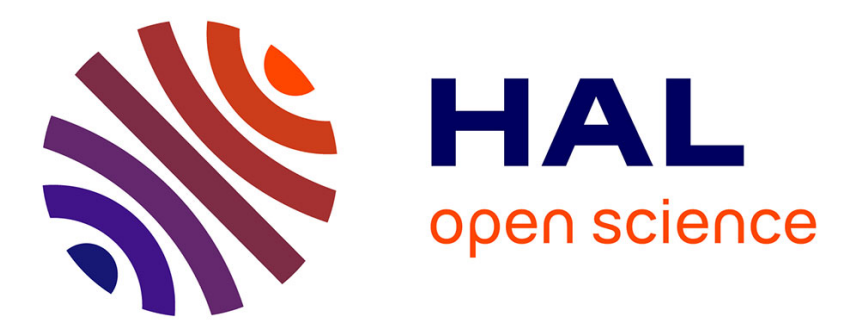

\title{
Plasma growth hormone levels during sexual maturation in diploid and triploid rainbow trout (Oncorhynchus mykiss)
}

J.P. Sumpter, R.F. Lincoln, V.J. Bye, J.F. Carragher, Pierre-Yves Le Bail

\section{- To cite this version:}

J.P. Sumpter, R.F. Lincoln, V.J. Bye, J.F. Carragher, Pierre-Yves Le Bail. Plasma growth hormone levels during sexual maturation in diploid and triploid rainbow trout (Oncorhynchus mykiss). General and Comparative Endocrinology, 1991, 83, pp.103-110. 10.1016/0016-6480(91)90110-R . hal02715823

\section{HAL Id: hal-02715823 \\ https://hal.inrae.fr/hal-02715823}

Submitted on 1 Jun 2020

HAL is a multi-disciplinary open access archive for the deposit and dissemination of scientific research documents, whether they are published or not. The documents may come from teaching and research institutions in France or abroad, or from public or private research centers.
L'archive ouverte pluridisciplinaire HAL, est destinée au dépôt et à la diffusion de documents scientifiques de niveau recherche, publiés ou non, émanant des établissements d'enseignement et de recherche français ou étrangers, des laboratoires publics ou privés. 


\title{
Plasma Growth Hormone Levels during Sexual Maturation in Diploid and Triploid Rainbow Trout (Oncorhynchus mykiss)
}

\author{
J. P. Sumpter, R. F. Lincoln, ${ }^{*}$ V. J. Bye, ${ }^{*}$ J. F. Carragher, and P. Y. Le Bail $\dagger$ \\ Department of Biology and Biochemistry, Brunel University, Uxbridge, Middlesex UB8 3PH, United \\ Kingdom; *Ministry of Agriculture, Fisheries and Food, Directorate of Fisheries Research, Fisheries \\ Laboratory, Lowestoft, Suffolk NR33 OHT, United Kingdom: and †Laboratoire de Physiologie des Poissons, \\ INRA, Campus de Beaulieu, 35042 Rennes Cédex, France
}

Accepted August 2, 1990

\begin{abstract}
Plasma growth hormone concentrations were determined in diploid and triploid rainbow trout of both sexes during sexual maturation. Diploid females grow large ovaries, whereas triploid female trout show no ovarian development. The plasma growth hormone concentration in triploid female trout remained low and unchanged throughout the study, whereas it rose slightly, but significantly, in the diploid females that matured, but not in those that remained immature. On the other hand, triploid males do develop testes like their diploid counterparts. In both groups spermiation was accompanied by a steady rise in the plasma growth hormone concentration. The results suggest that the elevated growth hormone concentration in mature male trout was a consequence not of reproduction per se, but of the loss of condition that accompanied spawning. This hypothesis was supported by the results from the females. Apart from a temporary loss in the mature diploids caused by stripping of the eggs, female trout did not lose condition, neither did they show any change in the plasma growth hormone concentration during the period when they ovulated. These results suggest that it was the nutritional insufficiency accompanying reproduction in male fish that caused the elevation in growth hormone concentration. In fact, a strong negative correlation between the plasma growth hormone concentration and the condition factor of the fish was observed. 1991 Academic Press. Inc.
\end{abstract}

It has long been recognised that there is an association between growth and reproduction in fish, as there is in other groups of vertebrates (reviewed by Le Bail, 1986). For example, larger trout are more likely to mature in any given year than are smaller fish of the same age; that is, early puberty is linked to a high growth rate. This association is certainly complex, and will be very difficult to untangle. However, certain specific aspects of the relationship between growth and reproduction are amenable to experimentation. One that has received some attention is the relationship (if any) between the hormones that regulate growth and those that regulate reproduction. Sexual maturation in salmonid fishes involves the development of very large gonads (especially the ovary, which can constitute
$25 \%$ of the body weight), and hence intuitively it seems likely that hormones that stimulate somatic growth will also be involved in gonadal growth. In fact, injected bovine growth hormone has been shown to stimulate ovarian growth, as well as somatic growth, in juvenile coho salmon (Higgs et al., 1976,1977). Further, both mammalian and salmon growth hormones enhance sex steroid production in vivo (Singh et al., 1988) and in vitro (Singh et al., 1988; Young et al., 1983). In turn, these steroids can be anabolic (reviewed in Higgs et al., 1982), i.e., they stimulate growth, demonstrating the close interrelationships between the reproductive hormones and those controlling growth.

Only a single study in fish has investigated plasma growth hormone levels during 
sexual maturation (Stacey et al., 1984). This reported that growth hormone levels in male white suckers (Catostomus commersoni) were not obviously related to changes in reproductive status (though these authors investigated the final stages of maturation only), whereas in female suckers the plasma growth hormone level increased significantly at ovulation, and remained elcvated following spawning.

To assess whether sexual maturation is accompanied by changes in the plasma growth hormone level, we conducted an experiment using rainbow trout that were approaching 2 years of age, when the majority were expected to mature. We used both diploid and triploid fish (Lincoln and Scott, 1983) of each sex because this allowed us to monitor some fish that did not show any gonadal growth, others that showed considerable, but not full, gonadal growth, and others that matured normally during the experiment, yet all were of the same age and genetic stock (Lincoln and Scott, 1984).

\section{MATERIALS AND METHODS}

Fish. Eggs of the "Butley" strain were obtained from a commercial trout farm. Fertilization took place on January 24,1985 , and triploidy was induced in approximately half the eggs by applying to them a heat shock at $28^{\circ}$ for $10 \mathrm{~min}$, starting $30 \mathrm{~min}$ after fertilization (Lincoln and Scott, 1983) and then returning them to water at $10^{\circ}$. The eggs and fry were reared in dechlorinated mains water at the Lowestoft laboratory and finally transferred as two separate groups of diploids and triploids to compartments $\left(9.4 \mathrm{~m}^{3}\right)$ of a raceway system (totalling $45 \mathrm{~m}^{3}$ ) in which mains water was recycled at the rate of 1 pass every $4 \mathrm{hr}$, with $10 \%$ replacement per day.

On 30/4/86 about 60 fish from each group were selected randomly and tagged with individually numbered Floy anchor tags (Floy Tagg Manufacturing Co. Ltd.) through the dorsal musculature. At this stage ploidy was confirmed in each fish by measurements of the long axis of erythrocyte nuclei (Wolters et al., 1982) obtained from blood smears fixed in ethyl alcohol and stained in 5\% Giemsa.

The fish were fed throughout on commercial trout pellets, twice daily, ad libitum. Over the experimental period a minimum water temperature of $10^{\circ}$ was maintained during the winter. Summer water temperature reached a maximum of $16.6^{\circ}$ in July 1986 .
Experimental design. Although growth data was collected over 2 years, from the fry stage right through until most diploid fish matured as 2-year-olds. blood samples for growth hormone determination were collected only over the final 8 months. Blood was first collected in October, when we predicted that the gonads would have been growing rapidly. Our experience suggested that at this time the gonadosomatic index (GSI) would have been around 1 in the males and 3 in the females (see Scott and Sumpter, 1989; Sumpter and Scott, 1989, for full details on the rate and timing of gonadal growth in rainbow trout). Blood samples were collected from all tagged fish (approximately 120 ) through the spawning season and well into the recovery period. At the end of the experiment, in May, all of the females were fully recovered from spawning, and most males had ceased spermiation.

Because the fish were tagged. it was possible to monitor individuals throughout the experiment. Initially 30 male and 27 female diploid fish, and 39 male and 20 female triploid fish, were tagged. We randomly selected 20 fish in each of the four groups for assessment of plasma growth hormone levels. Thus the initial sample size of each group was 20 at the beginning of the experiment. At the end of the experiment, in May 1987, 19, 13, 19, and 15, respectively, of these tagged fish were alive (trout are especially susceptible to disease when sexually mature; Pickering and Christie, 1981).

The last sampling of the males was performed on May 1, 1987, when they were showing signs of recovery from spawning (see Results). The last sampling of the females was 1 month earlier, on April 1, 1987. Sampling ceased then partly because the females had long since recovered from spawning (see Results), and partly because we wanted to minimise any further stress on the females, whose postspawning growth rate was of great interest to us.

Sampling. At monthly intervals all fish were netted and lightly anaesthetized in phenoxyethanol (Sigma, Poole, Dorset). Each fish was weighed (to the nearest g) and its total length measured (to the nearest $\mathrm{mm}$ ). A blood sample was then collected from the caudal sinus into heparinized syringes, and after centrifugation the plasma was frozen. While anaesthetized each fish was assessed for external signs of sexual maturity, such as an enlarged genital papilla and development of kype and colouration in males. The time of ovulation and spermiation was assessed by extrusion of eggs or milt under application of gentle pressure to the abdomen. All males, diploid and triploid, matured as 2-year-olds. None of the triploid females showed any signs of sexual development. Most of the diploid females matured as 2-year olds, but 6 did not (these would probably have matured for the first time as 3-year olds). The 20 diploid females selected for growth hormone analysis included all of these 6 immature diploid females, as well as 14 diploid females that did mature. 
Radioimmunoassay. The plasma growth hormone level was determined using the radioimmunoassay described by Le Bail et al. (1991). This assay is a homologous chinook salmon (O. tschawytscha) assay; however, plasma (and extracts of pituitary glands) from all Salmo and Oncorhychus genus species tested in this assay cross-react in a parallel manner to purified chinook growth hormone (Le Bail et al., 1991). The recent cloning of rainbow trout cDNAs for GHI and GHII, allowing prediction of their amino acid sequences (Rentier-Delrue et al.. 1989), has enabled these to be compared to the sequences of growth hormones from other salmonids. This comparison revealed that all the salmonid growth hormones fully characterised to date are structurally very similar (Rentier-Delrue et al., 1989). These findings suggest that growth hormone measurements made in this study, using a heterologous assay. are valid.

Analysis of results. The coefficient of condition (condition factor; $K$ ) of fish was obtained from the equation: $K=$ [fish weight (in grams)/fish length ${ }^{3}$ (in $\mathrm{cm})] \times 100$. Changes in the weight, condition factor, and plasma $\mathrm{GH}$ level of trout during the study period were analysed by one-way analysis of variance (Minitab). The relationship between plasma growth hormone level and condition factor was shown most clearly by transformation of the growth hormone values by a log function prior to plotting. Correlation values were calculated from the transformed growth hormone data and the (untransformed) condition factor data using Minitab; the values were taken from a standard correlation coefficient table. Only the weight and length data collected during the period when plasma growth hormone levels were measured have been used for the analysis and the figures in this paper.

\section{RESULTS}

At the beginning of the study period the two groups of males each weighed significantly more than the groups of females (Fig. 1). This disparity was probably a consequence of the high levels of androgens present in the males during sexual maturation (Scott and Sumpter, 1989), because these hormones are strongly anabolic (reviewed in Higgs et al., 1982). During the next 8 months only the triploid female and immature diploid female fish continued to steadily increase in weight (Fig. 1), leading to a doubling of their weight during the course of the experiment. Diploid and triploid male fish, and the mature diploid female fish, all went through a period during

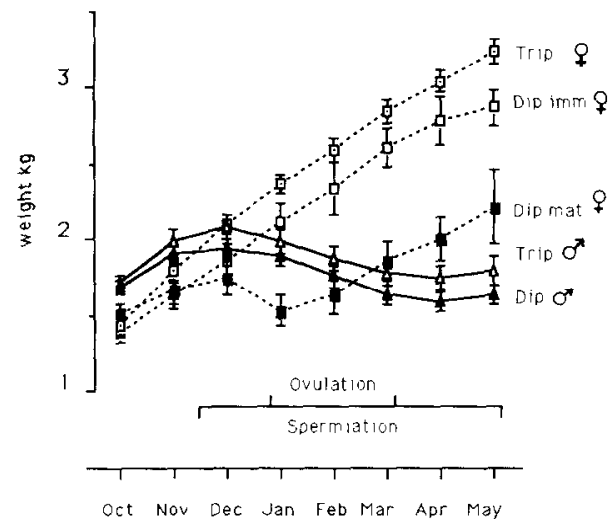

FIG. 1. Growth rates of diploid and triploid rainbow trout during sexual maturation. Not all of the diploid females matured as 2-year-olds. Results are expressed as mean \pm SEM.

which they lost weight (Fig. 1). This period of weight loss, which was brief for the mature diploid female fish, occurred during the spawning season, and was caused primarily by the removal of ovulated eggs. Thereafter the mature diploid female fish recommenced growing, and at the end of the experiment (in May) they were significantly heavier than at the beginning (the preceding October). On the other hand, both diploid and triploid males showed a prolonged period of 4 months during which they progressively lost weight; this coincided with spermiation (Fig. 1). Only at the very end of the experiment did this weight loss halt and the males begin to put on weight again.

The triploid female and immature diploid female fish maintained a high condition factor (around 1.5) throughout the experiment (Fig. 2). Initially the diploid mature females also had a high condition factor, but this fell significantly $(P<0.001)$ at the time of ovulation before recovering to its former value. The condition factor of both groups of males fell throughout the course of the experiment and the loss was especially pronounced during the extended period (5 months) of spermiation (Fig. 2). Only at the very end of the experiment was there any indication that the male fish had declined to 


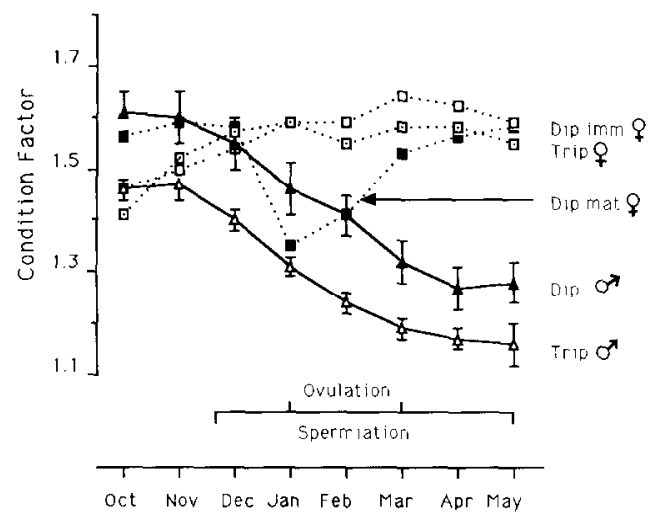

FIG. 2. Changes in condition factor of diploid and triploid rainbow trout during sexual maturation. Not all of the diploid females matured as 2-year-olds. To prevent cluttering of the diagram, only the standard errors on the data from the diploid and triploid males are shown. All the other standard errors were of comparable magnitude.

their lowest condition factor and subsequently would recover condition.

Basal plasma growth hormone levels were low (less than $1 \mathrm{ng} \mathrm{ml}^{-1}$ ) during the study. No significant effect of time on the plasma growth hormone level was detected for triploid female fish or diploid immature female fish; levels remained low throughout the study (Fig. 3A). However, there were significant effects of time on plasma growth hormone levels for triploid male fish $(P<$ 0.05 ), and diploid male and mature female fish $(P<0.01$ in both cases). This increase was most marked in the two groups of males, in which the plasma growth hormone level rose approximately 10 -fold, from $0.3 \mathrm{ng} \mathrm{ml}^{-1}$ to around $3 \mathrm{ng} \mathrm{ml}^{-1}$. This pronounced rise occurred during the period of spermiation (Fig. 3A). The plasma growth hormone level of the diploid mature females rose from $0.3 \mathrm{ng} \mathrm{ml}^{-1}$ at the beginning of the study to $0.7 \mathrm{ng} \mathrm{ml}^{-1}$ at the end (Fig. 3B).

For all 5 groups of fish the relationship (correlation) between plasma growth hormone level and condition factor (for each fish at each month) was assessed. Significant, negative correlations between these
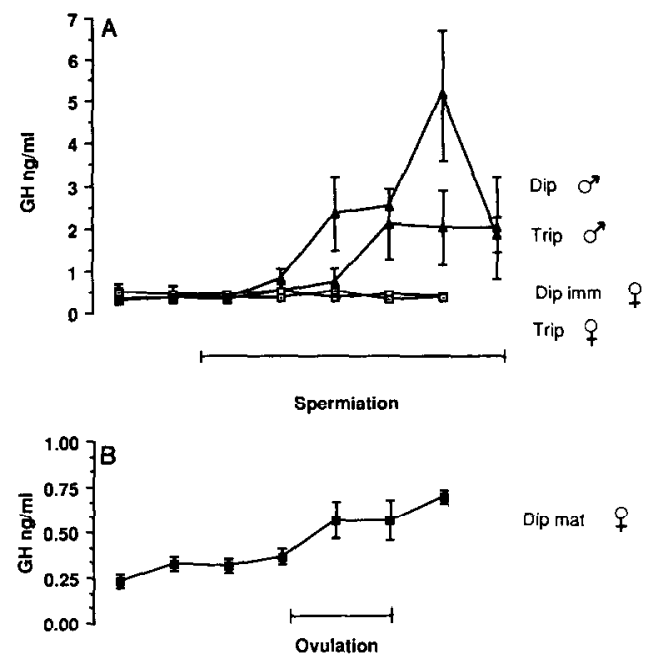

Oet Nor Dec Jan Feb Mar Apr May

Fig. 3. Changes in the plasma growth hormone concentration of diploid and triploid rainbow trout during sexual maturation. Not all of the diploid females matured as 2-year-olds. Results are expressed as mean \pm SEM. Where standard errors are not shown they were within the size of the symbol. The results for diploid mature females (B) have been plotted on a different scale compared to the other group (A) to represent clearly the changes in plasma growth hormone level that occurred in this group.

two indices were found for diploid male, triploid male, diploid mature female $(P<$ 0.001 in all cases; Fig. 4a,b,c), and diploid immature female $(P<0.05$; Fig. $4 d)$ fish. No significant correlation was detected for triploid female fish (Fig. 4e).

A similar analysis (plasma growth hormone level against condition factor) on a monthly basis was investigated. Only the data from the male fish, of both ploidy levels, are shown here (Fig. 5). It can be seen that the same trends were observed in both groups of fish. Condition factor fell (the points drift from right to left) as the study progressed and this was accompanied by the correlation between condition factor and plasma growth hormone level getting progressively stronger. These effects were most obvious and pronounced in the triploid males, in which the correlation was not 

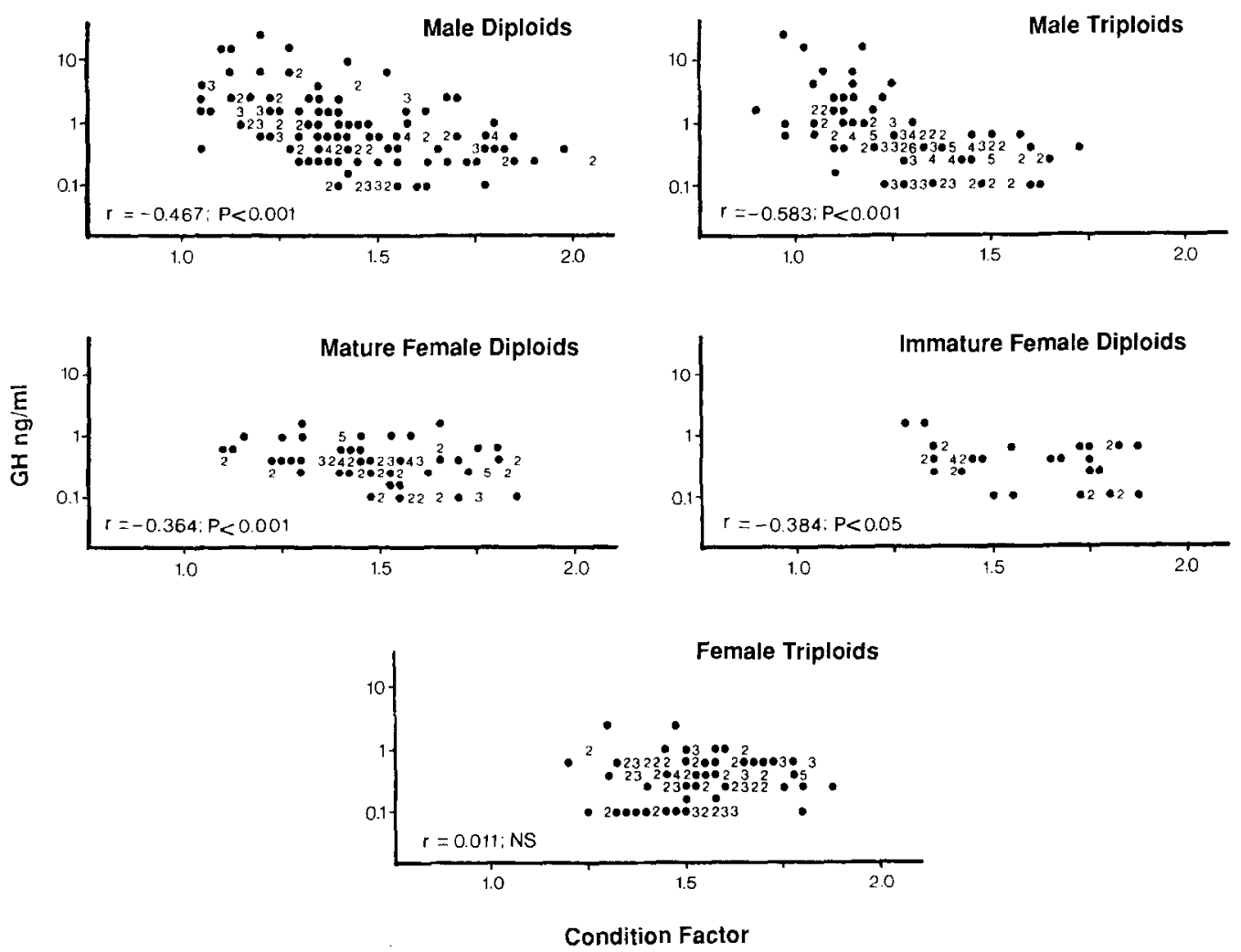

FIG. 4. The relationship between the plasma growth hormone concentration and the condition factor of diploid and triploid rainbow trout during sexual maturation. A dot represents a single fish, whereas a number signifies more than one fish. The levels of significance of the regressions are indicated. Note that plasma growth hormone concentrations are plotted on a log scale.

significant in October but became so by February $(P<0.05)$ and proceeded to get stronger $(P<0.01$ in April and May; Fig. 5).

\section{DISCUSSION}

The data demonstrate that although plasma growth hormone levels may be elevated during sexual maturity, high levels are not a prerequisite for successful maturation. This contention is supported most clearly by considering in detail the data obtained from the diploid mature female trout. Although the ovaries of this group grew rapidly during the first half of the study (from October to January), during which the GSI would have increased from about 3 to 20 (Sumpter and Scott, 1989), their plasma growth hormone level remained low $\left(\sim 0.3 \mathrm{ng} \mathrm{ml}^{-1}\right)$. None of the fish had ovulated when they were sampled in December, but 13 out of the 14 had by the time they were sampled a month later, in early January. The corresponding plasma growth hormone levels at these two times were $0.32 \pm 0.04$ and $0.37 \pm 0.04 \mathrm{ng} \mathrm{ml}^{-1}$, respectively. Thus, ovulation was not accompanied by any significant change in the plasma growth hormone level. Only after ovulation did the plasma growth hormone level rise significantly, though the change was relatively small (it doubled). Most of this increase $(0.37 \pm 0.04$ to $0.57 \pm 0.10 \mathrm{ng}$ $\mathrm{ml}^{-1}$ ) occurred between January and February, during the period when the fish had their lowest condition factor. Overall, the 

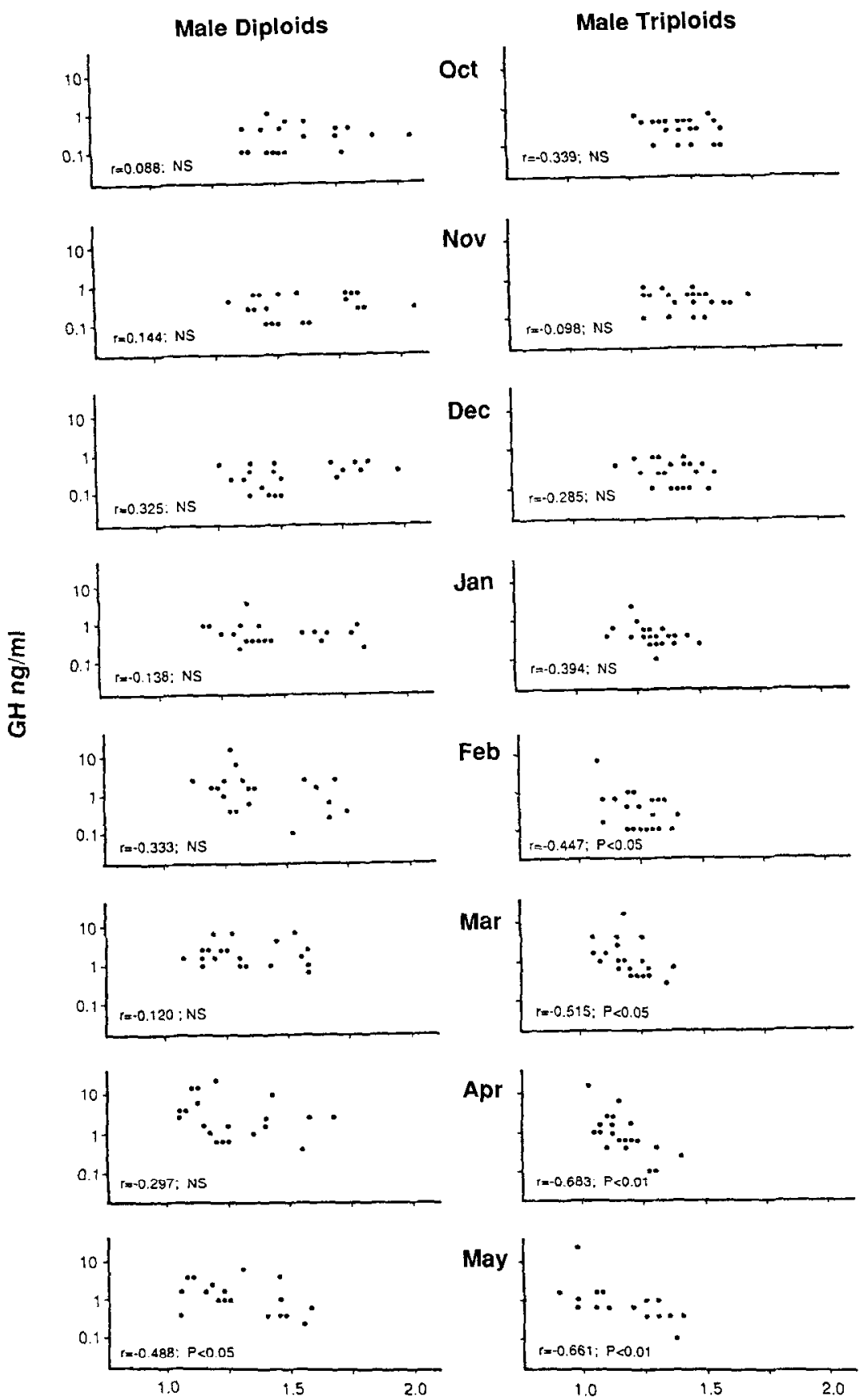

\section{Condition Factor}

Fig. 5. Changes in the relationship between the log plasma growth hormone concentration and condition factor of diploid and triploid male rainbow trout during sexual maturation. Each month has been plotted separately to demonstrate the change in the relationship with time. The levels of significance of the regressions are indicated. $n=20$ in most cases. Note that plasma growth hormone concentrations are plotted on a log scale. 
data suggest that full ovarian growth is not accompanied by elevated growth hormone levels. However, any loss of condition as a consequence of spawning is accompanied by elevated growth hormone levels.

This explanation is supported by the results of the males. Unlike the situation in females, triploid males do develop large gonads, accompanied by elevated sex steroid levels (Lincoln and Scott, 1984). Although none of the diploid males were running at the beginning of the study, 18 out of the 20 were a month later, in mid-November, and all were in December. Over this period the plasma growth hormone level of the diploid males remained unchanged $\left(\sim 0.3 \mathrm{ng} \mathrm{ml}^{-1}\right)$. Thus, as observed with the diploid mature females, the later stages of gonadal growth, and gamete release, were not accompanied by elevated plasma growth hormone levels. However, subsequently, during the prolonged period of spermiation, the plasma growth hormone level rose appreciably. Again, this rise was accompanied by a pronounced loss of condition, the two indices being closely negatively correlated.

Similar results were observed with the triploid males. It is usually impossible to express milt from triploid males (Lincoln and Scott, 1984), and hence it was not possible to assess their degree of testicular development without killing the fish. However, the timing of testicular development is considered to be similar in both diploid and triploid male trout of the same stock (Lincoln and Scott, 1984; Benfey et al., 1989). 'Thus, it is very likely that full gonadal development was reached in the triploid male trout without any accompanying change in the plasma growth hormone level. Like the diploid males, these fish also suffered a dramatic loss of condition during the following months, which was accompanied by an elevated growth hormone level.

Our proposition that the nutritional insufficiency which occurs during reproduction, especially in males, is the reason for the elevated growth hormone levels, rather than reproduction per se, is supported by our results on the effects of starvation. We have shown that starvation, and the accompanying loss of condition, is associated with elevated growth hormone levels (Sumpter et al., 1991). It is likely that the elevated growth hormone levels associated with nutritional insufficiency serve to mobilize lipid reserves to supply energy (Sheridan, 1986,1988; Sumpter et al., 1991).

It is difficult to compare meaningfully our results with those of Stacey et al. (1984). We determined the plasma growth hormone level during the major phase of gonadal growth, spawning, and subsequent recovery, a period of 8 months in all. Stacey et al. (1984) determined plasma growth hormone concentrations in white suckers as they entered a spawning stream from a lake, during spawning, and on return to the lake, covering a period of only 2 months. Further, we monitored the condition of our fish, whereas they did not. Nevertheless, there are some similarities in the two sets of data. Stacey et al. (1984) observed relatively constant plasma growth hormone levels throughout the spawning season in males. In females, however, plasma growth hormone levels were lowest in prespawning females, were increased significantly at ovulation, and remained high in spent females. Thus, in our study we observed elevated growth hormone levels in males, but not females, whereas Stacey et al. (1984) reported the opposite. Without knowing more about the reproductive cycle of white suckers, it is not possible to assess whether a similar reason (nutritional insufficiency) was the cause in both cases.

Paradoxically, our data show that trout with low plasma growth hormone levels can grow rapidly (the triploid females and the diploid, immature females), whereas fish with high plasma growth hormone levels may grow slowly, if at all (the diploid and triploid males). We observed a similar negative association between growth rate and plasma growth hormone level in another 
study concerned with the effects of starvation on rainbow trout (Sumpter et al., 1991); possible explanations are discussed by Sumpter et al. (1991).

\section{ACKNOWLEDGMENTS}

We thank SERC and M $\Lambda F F$ for supporting the research, and Mr. P. Hardiman for care and maintenance of the fish.

\section{REFERENCES}

Benfey, T. J., Dye, H. M., Solar, I. I., and Donaldson, E. M. (1989). The growth and reproductive endocrinology of adult triploid Pacific salmonids. Fish Physiol. Biochem. 6, 113-120.

Higgs, D. A., Donaldson, E. M., Dye, H. M., and McBride, J. R. (1976). Influence of bovine growth hormone and L-thyroxine on growth, muscle composition, and histological structure of the gonads. thyroid, pancreas and pituitary of coho salmon (Oncorhynchus kisutch). J. Fish. Res. Board Can. 33, 1585-1603.

Higgs, D. A., Fagerlund, U. H. M., McBride, J. R., Dye, H. M., and Donaldson, E. M. (1977). Influence of combinations of bovine growth hormone. $17 \alpha$-methyltestosterone, and L-thyroxine on growth of yearling coho salmon (Oncorhynchus kisutch). Can. J. Zool. 55, 1048-1056.

Higgs, D. A., Fagerlund, U. H. M., Eales, J. G., and McBride, J. R. (1982). Application of thyroid and steroid hormones as anabolic agents in fish culture. Comp. Biochem. Physiol. B73, 143-176.

Le Bail, P. Y. (1986). Growth-reproduction interaction in salmonids. In "Reproduction in Fish. Basic and Applied Aspects in Endocrinology and Genetics," pp. 91-108. Proceedings of the French/Israeli symposium, Tel Aviv, November 10-12, 1986. INRA, Paris.

Le Bail, P. Y., Sumpter, J. P., Carragher, J. F., Mourot, B., Niu, P. D., and Weil, C. (1991). Development and validation of a highly sensitive radioimmunoassay to chinook salmon (Oncorhynchus tshaw'stsha) growth hormone. Gen. Comp. Endocrinol. 82.

Lincoln, R. F., and Scott, A. P. (1983). Production of all-female triploid rainbow trout. Aquaculture 30, 375-380.

Lincoln, R. F., and Scott. A. P. (1984). Sexual maturation in triploid rainbow trout, Salmo gairdneri Richardson. J. Fish Biol. 25, 385-392.

Pickering, A. D., and Christie, P. (1981). Changes in the concentrations of plasma cortisol and thyroxine during sexual maturation of the hatchery- reared brown trout, Salmo trutta L. Gen. Comp. Endocrinol. 44, 487-496.

Rentier-Delrue, F., Swennen, D., Mercier, L., Lion, M., Benrubi, O., and Martial, J. A. (1989). Molecular cloning and characterization of two forms of trout growth hormone cDNA: Expression and secretion of tGH-II by Escherichia coli. DNA 8, 109-117.

Scott, A. P., and Sumpter, J. P. (1989). Seasonal variations in testicular germ cell stages and in plasma concentrations of sex steroids in male rainbow trout (Salmo gairdneri) maturing at 2 years old. Gen. Comp. Endocrinol. 73, 46-58.

Sheridan, M. A. (1986). Effects of thyroxine, cortisol, growth hormone, and prolactin on lipid metabolism of coho salmon. Oncorhynchus kisutch, during smoltification. Gen. Comp. Endocrinol. 64, 220-238.

Sheridan, M. A. (1988). Lipid dynamics in fish: Aspects of absorption, transportation, deposition and mobilization. Comp. Biochem. Physiol. B90, $679-690$.

Singh, H., Griffith, R. W.. Takahashi, A., Kawauchi, H., Thomas, P., and Stegoman, J. J. (1988). Regulation of gonadal steroidogenesis in Fundulus heteroclitus by recombinant salmon growth hormone and purified salmon prolactin. Gen. Comp. Endocrinol. 72, 144-153.

Stacey, N. E., Mackenzie, D. S., Marchant, T. A., Kyle, A. L., and Peter, R. E. (1984). Endocrine changes during natural spawning in the white sucker, Catostomus commersoni. I. Gonadotropin, growth hormone, and thyroid hormones. Gen. Comp. Endocrinol. 56, 333-348.

Sumpter, J. P., and Scott, A. P. (1989). Seasonal variations in plasma and pituitary levels of gonadotrophin in males and females of two strains of rainbow trout (Salmo gairdneri). Gen. Comp. Endocrinol. 75, 376-388.

Sumpter. J. P., Le Bail. P. Y.. Pickering, A. D., Pottinger. T. G., and Carragher, J. F. (1991). The effect of starvation on growth and plasma growth hormone concentrations of rainbow trout, Oncorhynchus mykiss. Gen. Comp. Endocrinol. 82.

Wolters. W. R., Chrisman, C. L.. and Libey, G. S. (1982). Erythrocyte nuclear measurements of diploid and triploid channel catfish, Ictalurus punctatus (Rafinesque). J. Fish Biol. 20, 253-258.

Young, G., Ueda, H., and Nagahama, Y. (1983). Estradiol- $17 \beta$ and $17 \alpha, 20 \beta$-dihydroxy-4-pregnen3-one production by isolated ovarian follicles of amago salmon (Oncorhynchus rhodurus) in response to mammalian pituitary and placental hormones and salmon gonadotrophin. Gen. Comp. Endocrinol. 52, 329-335. 